\title{
RESENHA
}

DOI: http://dx.doi.org/10.1590/So034-759020160210

\section{DEFININDO AS QUALIDADES DE UMA BOA ESTRATÉGIA: LIÇÕES DO ESTRATEGISTA}

\section{GOOD STRATEGY/BAD STRATEGY: The difference and why it matters}

Richard Rumelt. New York: Crown Business, 2011. 321 p.

Em 1917, durante a Primeira Guerra Mundial, nas cercanias da Vila de Passchendaele, 0 General Douglas Haig planejou um ataque contra as forças alemãs. Realizou extenso trabalho de planejamento e motivação de sua equipe e iniciou a ofensiva. Como resultado, em apenas três meses, levou 70 mil soldados à morte e deixou outros 250 mil feridos. Casos como esse, classificado por Winston Churchill como "um desesperado gasto de valor e de vida, de futilidade sem igual”, são usados por Richard Rumelt neste impactante, pragmático e bem-escrito livro para ilustrar as estratégias ruins e boas, aplicadas às empresas, entidades sem fins lucrativos e organizações militares. Os exemplos usados variam da Apple à General Motors, das duas guerras no Iraque à do Afeganistão, de um pequeno supermercado ao Walmart, da Nvidia à Silicon Graphics, da Getty Trust ao Los

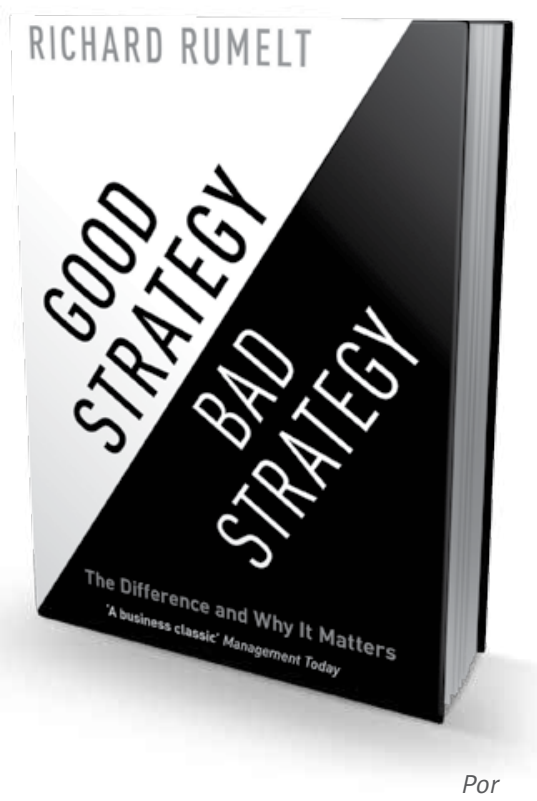

Carlos A. Caldeira carlosacf@insper.edu.br Professor do Instituto de Ensino e Pesquisa São Paulo - SP, Brasil

David Kallás davidk@insper.edu.br Professor do Instituto de Ensino e Pesquisa - São Paulo - SP, Brasil
Angeles Unified School District, da Cisco Systems à Paccar e do Global Crossing à crise financeira de 2008. Em face de uma enxurrada de publicações reforçando a (merecida) relevância da execução, o autor recoloca a qualidade da estratégia em seu devido lugar de importância. "O propósito deste livro é alertá-lo sobre as dramáticas diferenças entre estratégias boas e ruins e apoiá-lo a formular estratégias boas", afirma.

A motivação para esta obra veio da extensa experiência do autor, tanto acadêmica quanto como consultor de empresas. Com carreira iniciada em 1966, Rumelt é um dos principais pesquisadores em estratégia do mundo, sendo precursor de linhas de pesquisa como os estudos de antecedentes do desempenho (Strategic Management Journal, 1991), a visão baseada em recursos (The Bell Journal of Economics, 1982) e a estratégia corporativa (Strategic Management Journal, 1982; Journal of Economic Behaviour \& Strategy, 1994). Seus estudos, entre outros, enfatizaram a importância da firma e das ações gerenciais (em outras palavras, da estratégia) no resultado das organizações. Atuou como consultor por muitos anos, a ponto de ser considerado pela McKinsey "um gigante no campo da estratégia" e "o estrategista dos estrategistas". Para ele, uma estratégia boa deve sempre parecer simples e óbvia. Entretanto, afirma, com base em sua experiência, que estratégias boas são exceções nas organizações.

Tanto a literatura acadêmica como a executiva tendem a se concentrar mais em casos de sucesso que de fracasso. São comuns estudos de casos, livros e reportagens analisando grandes blockbusters como Google, Apple e Facebook. Entretanto, é mais fácil aprender com casos em que a estratégia não deu certo. Isso porque a análise de casos bem-sucedidos corre o risco de ser prejudicada por fenômenos como a ambiguidade causal, a dependência da trajetória e a complexidade social, na linha proposta por Barney (Firm Resources and Sustained Competitive Advantage, Journal of Ma- 
nagement, 1991) e complementada por Peteraf (The Cornerstone of Competitive Advantage: A Resource-Based View, Strategic Management Journal, 1993 ). Afinal de contas, o sucesso da Apple deve-se a Steve Jobs, à excelência operacional, ao design ou à equipe da empresa? Daí a relevância e a ousadia desta obra, que busca também em casos de fracasso fontes de aprendizado.

O livro é dividido em três partes. Elas são intituladas respectivamente: estratégias boas e ruins; as fontes de poder; e pensando como um estrategista. A primeira parte aborda as diferenças entre estratégias ruins e boas. 0 autor argumenta que, infelizmente, a maioria das empresas ou não tem estratégia, ou tem estratégias ruins. Essas estratégias ruins têm algumas causas ou características peculiares. A primeira delas é a dificuldade dos gestores em realmente encarar os problemas estratégicos vividos por suas firmas. É mais fácil, argumenta Rumelt, não lidar com essas questões penosas. Outra causa de estratégias ruins é confundir uma estratégia com um apanhado de objetivos (na verdade, metas). Ter metas de crescer $10 \%$ em vendas ao ano e aumentar o retorno sobre ativos para $7 \%$ em três anos, defende o autor, não constitui uma estratégia. A terceira característica de uma estratégia ruim seria a existência de objetivos confusos e conflitantes, ou, ainda, impraticáveis. Finalmente, a quarta marca de uma estratégia ruim é caracterizada pelo uso de chavões e linguagem rebuscada, por vezes beirando o esoterismo, para tentar passar uma imagem de estratégia robusta, quando na verdade esta é fraca em análise e conteúdo. 0 pesquisador argumenta principalmente contra os planejamentos estratégicos baseados em modelos prontos, sem deliberação. 0 autor, em seguida, argumenta quais são as características de uma boa estratégia. O cerne de uma boa estratégia, segundo ele, é composto de três partes: um diagnóstico da situação estratégica, uma diretriz norteadora e um conjunto coerente de ações a serem tomadas. Simples e direto ao ponto.

A segunda parte do livro está voltada a explorar as fontes de poder de uma estratégia vencedora. Entender esses mecanismos e situações, que fazem a diferença entre uma estratégia boa e uma ruim, é parte dessa missão de formar estrategistas. Enquanto, na primeira parte, a simplicidade e robustez marcaram o passo, na segunda, a organização não é mais tão enxuta. 0 autor explora uma série dessas fontes de poder: alavancagem, objetivos factíveis, a sinergia de elos de um sistema estratégico (à semeIhança do argumento de Porter em 1996), foco, a armadilha do crescimento a qualquer custo, as mudanças estruturais de um setor, as considerações sobre as respostas dos competidores, e, ainda, como a inércia e entropia organizacionais atrapalham a estratégia. São todos itens importantes, sem dúvida, mas o fio condutor dessa parte fica confuso e solto. 0 capítulo final dessa segunda parte é um estudo de caso da empresa de tecnologia Nvidia, especializada em placas gráficas para PC. 0 caso descreve a estratégia da Nvidia de vencer pela capacidade de desenvolvimento rápido da tecnologia. 0 estudo é completo e atual. Recentemente, a Nvidia lançou uma nova família de placas gráficas com salto enorme em termos de capacidade gráfica e consumo de energia, e a resposta estratégica será um grande desafio para a concorrente Radeon (AMD).

A terceira parte é dedicada a explicar como deveria pensar um estrategista e quais os modelos mentais mais adequados. 0 pesquisador argumenta que estratégia é muito semelhante a geração e teste de hipóteses, e dedica um capítulo inteiro a esse ponto. O segundo ponto é a necessidade de escolher o que fazer, enquanto se abre mão das coisas menos importantes. É o clássico argumento dos trade-offs, defendido aqui como uma necessidade diante da existência de recursos cognitivos finitos por parte do tomador de decisão. Finalmente, no último capítulo, usando exemplos históricos, Rumelt chama a atenção para algumas decisões estratégicas questionáveis que foram tomadas na carona do efeito manada, por se tratar de modismos.

No geral, o livro tem muito mais acertos do que erros. As críticas podem voltar-se à falta de ritmo da segunda parte do livro. Outros podem argumentar que, de fato, não há nada de novo (alinhamento, trade-off, foco, mudanças estruturais no setor, armadilha do crescimento, fraquezas e fortalezas). Finalmente, pode-se apontar que Rumelt, que tanto demoniza os modelos, acaba propondo um. Entretanto, as qualidades, de longe, superam essas críticas. A estratégia ruim, infelizmente, não é uma singularidade americana, e aplica-se à nossa realidade. A derrocada no Grupo $X$, os investimentos frustrados na produção do etanol ou o Plano Nacional de Educação são exemplos a serem lembrados. 0 autor coleciona vários assuntos relativos a estratégia e os organiza e explica claramente. Ele também consegue recuperar a discussão sobre a formulação estratégica, num argumento que engloba tanto formulação como execução sob o mesmo guarda-chuva. Também discute a estratégia como diagnóstico, geração e teste de hipóteses, e o faz de uma maneira simples. Tudo isso elegantemente narrado e também permeado por um grande número de exemplos. Alguns são clássicos conhecidos. E tornaram-se clássicos por uma razão. Porém, outros exemplos são resultado de sua experiência, interação com estrategistas reconhecidos, ou, ainda, uso da análise histórica como forma de aprendizado. Sem dúvida, o livro é peça recomendada para acadêmicos e praticantes da estratégia. 